First- Year Technical Progress Report:

\title{
Chemical Decomposition of High Level Nuclear Waste Storage/Disposal Glasses Under Irradiation
}

Research performed for the DOE under Interagency Agreement No. DE-AI07-96ER45619

\section{David L. Griscom, Principal Investigator}

Celia I. Merzbacher, Co-Investigator

The objective of this research is to use the sensitive technique of electron spin resonance (ESR) to look for evidence of radiation-induced chemical decomposition of vitreous forms contemplated for immobilization of plutonium and/or high-level nuclear wastes, to interpret this evidence in terms of existing knowledge of glass structure, and to recommend certain materials for further study by other techniques, particularly electron microscopy and measurements of gas evolution by high-vacuum mass spectroscopy.

Previous ESR studies had demonstrated that an effect of $\gamma$ rays on a simple binary potassium silicate glass was to induce superoxide $\left(\mathrm{O}_{2}^{-}\right)$and ozonide $\left(\mathrm{O}_{3}{ }^{-}\right)$as relatively stable product of long-term irradiation Accordingly, some of the first experiments performed as a part of the present effort involved repeating this work. A glass of composition $44 \mathrm{~K}_{2} \mathrm{O}$ : $56 \mathrm{SiO}_{2}$ was prepared from reagent grade $\mathrm{K}_{2} \mathrm{CO} 3$ and $\mathrm{SiO}_{2}$ powders melted in a $\mathrm{Pt}$ crucible in air at $1200^{\circ} \mathrm{C}$ for $1.5 \mathrm{hr}$. A sample irradiated to a dose of $1 \mathrm{MGy}\left(1 \mathrm{MGy}=10^{8} \mathrm{rad}\right)$ indeed yielded the same ESR results as before.' To test the notion that the complex oxygen ions detected may be harbingers of radiation-induced phase separation or bubble formation, a small-angle neutron scattering (SANS) experiment was performed. SANS is theoretically capable of detecting voids or bubbles as small as $10 \AA$ in diameter. A preliminary experiment was carried out with the collaboration of Dr. John Barker (NIST). The SANS spectra for the irradiated and unirradiated samples were indistiguishable. A relatively high incoherent background (probably due to the presence of protons) may obscure scattering from small gas bubbles and therefore decrease the effective resolution of this technique. No further SANS experiments are planned at this time. 
Studies of actual model nuclear waste glasses focussed initially on a suite of samples provided by N.E. Bibler of the Westinghouse Savannah River Co., comprising two Defense Waste Processing Facility (DWPF) borosilicate compositions, one experimental lanthanum silicate glass, and an iron phosphate glass (designated $\mathrm{PO}_{4}-3$ ) of composition $50 \mathrm{P}_{2} \mathrm{O}_{5}$ $20 \mathrm{Fe}_{2} \mathrm{O}_{3}-23 \mathrm{Li}_{2} \mathrm{O}-7 \mathrm{CeO}_{2}$. Several other experimental iron phosphate glasses, including two high-iron binary compositions, were subsequently provided by $\mathrm{M}$. Mesko of the University of Missouri-Rolla. The Savannah River samples were matched pairs of homogeneous sieved powders which were either unirradiated or exposed to ${ }^{60}$ ( Coy-ray doses of $30 \mathrm{MGy}$; the Missouri-Rolla samples have not yet been irradiated.

The ESR spectra of the DWPF glasses FA-13 and EA (Fig. 1f and g, respectively) are interpreted as arising primarily from isolated $\mathrm{Fe}^{3+}$ ions, ion pairs, or precipitated ferrites. Further studies will be required to determine how much of each species contributes to different parts of the spectra. A study of the temperature dependence of spectral shape and intensity presently suggests that the low-field parts of the DWPF glass spectra arise from $\mathrm{Fe}^{3+}$ ion pairs. No definitive differences have yet been discerned between the irradiated and un-irradiated DWPF samples, although in principle it is expected that radiation-generated free electrons should trap on $\mathrm{Fe}^{3+}$ ions, reducing their numbers and creating one $\mathrm{Fe}^{2+}$ ion per trapped electron. The $\mathrm{Fe}^{2+}$ ions are not detected by ESR under present conditions. As irradiation did not appear to effect the ESR line shape, possible effects on the intensity of the signal were investigated by running 24 spectra for 3 replicate irradiated samples and 24 spectra for 3 replicate un-irradiated ones, leading to a measurement of $\left[\mathrm{Fe}^{3+}\right]_{\text {irrad }}:\left[\mathrm{Fe}^{3+}\right]_{\text {unirrad }}=0.987 \pm 0.050$. Most of the large rms variance relates to unaccountable differences between supposedly equivalent replicate aliquots. Further efforts are planned to improve this number, including irradiating samples to substantially higher doses. Also, a concerted search will be mounted for the oxygen-associated trapped-hole centers which would be the counterparts of any electrons trapped in iron ions,

By far the most interesting of the glasses investigated to date are the iron phosphates, currently in considerable favor for plutonium immobilization because of their high chemical durabilities. Figure 1 includes the room-temperature X-band ESR spectra recorded for several un-irradiated air-melted iron phosphate glasses, including the Savannah-Riverprovided PO,-3 glass (Fig. lb) and three of the glasses received from the University of Missouri-Rolla (Fig. 1a,c,d). Table 1 gives the nominal " $\mathrm{Fe}_{2} \mathrm{O}_{3}$ " and " $\mathrm{P}_{2} \mathrm{O}_{5}$ " contents of the starting materials from which these glasses were melted; as will be discussed below, the actual oxygen stoichiometry of the finished glasses may be different from those implied by these notations. It can be seen from the figure that all of the iron phosphate glasses display very broad, smoothly shaped resonances, which (for historical reasons to be mentioned) we denote the "X resonance." Glass PO,-3 also displays a sharper signal at the center, which we call the " $\mathrm{Z}$ resonance" (see Fig. lb). These distinctive signals are not recorded for the borosilicate or lanthanum-silicate compositions. Moreover, only the iron phosphate glass with the lowest iron-to-phosphorus ratio displays any ESR features in common with the phosphorus-free glasses (Fig. 1d). 
Table 1. Compositional data for several iron phosphate glasses.

\begin{tabular}{|c|c|c|c|}
\hline Glass Designation & $\mathrm{Fe}_{2} \mathrm{O}_{3}$ & $\mathrm{P}_{2} \mathrm{O}_{5}$ & other \\
\hline FCsSr3 (Fig. 1a) & 28.5 & 46.9 & 75.4 \\
\hline $\mathrm{PO}_{4}-3 \quad$ (Fig. 1b) & 20.5 & 49.4 & 69.9 \\
\hline (Fig. 1c) & 25.0 & 75.0 & 0 \\
\hline C-112 (Fig. 1 d) & 7.5 & 40.0 & 52.5 \\
\hline (Fig. 3) & 40.0 & 60.0 & 0 \\
\hline
\end{tabular}

The $\mathrm{X}$ and $\mathrm{Z}$ resonances were computer simulated, demonstrating their $\mathrm{g}$ values to lie near 2.0 (2.0028 in the latter case) and determining their line shapes to be nearly perfect Lorentzians with widths $\sigma_{\mathrm{L}}(\mathrm{X}) \approx 300-600 \mathrm{mT}$ and $\sigma_{\mathrm{L}}(\mathrm{Z}) \approx 30 \mathrm{mT}$ at $300 \mathrm{C}$. The X-resonance intensities appear to correlate linearly with $\left[\mathrm{Fe}_{2} \mathrm{O}_{3}\right] /\left[\mathrm{P}_{2} \mathrm{O}_{5}\right]$ and, calculated as spin- $1 / 2$ states, reach a limiting value of $\sim 1$ spin per phosphorus in air-melted glasses (see Fig. 2). While the data of Fig. 2 are consistent with the notion that the $\mathrm{X}$ resonance arises from (presumably ferric) iron ions in the iron phosphate glasses, it is noted that only $10 \%$ of the $\mathrm{Fe}^{3+}(\mathrm{S}=5 / 2)$ present would be required to account for these intensities.

Figure 3 presents room-temperature ESR spectra for glasses of type F-43 (see Table 1) melted under different atmospheres: (a) air, (b) bubbled oxygen, and (c) $90 \%$ forming gas-10\% air (forming gas is an $\mathrm{H}_{2}-\mathrm{N}_{2}$ mixture). On going from (a) to (b) the $\mathrm{X}$ resonance narrows dramatically but does not lose intensity (as determined by double integration of the illustrated derivative curves); the $\mathrm{Z}$ resonance also increases in intensity, though it remains two orders of magnitude weaker than the $\mathrm{X}$. But on going from either of the oxidizing atmospheres (a) or (b) to the reducing atmosphere (c), it is seen that the $X$ resonance disappears, to be replaced by a $\mathrm{Z}$ resonance which is 35 times weaker than the $\mathrm{X}$ resonances of (a) or (b). Figure 4 plots the overall ESR intensities (X plus Z) for these three glass melts versus the ratio $\left[\mathrm{Fe}^{3+}\right] /\left[\mathrm{Fe}^{3+}\right]+[\mathrm{Fe} "+]$ determined by Mössbauer spectroscopy (data provided by G.K. Marasinghe, U. of Missouri-Rolla). The unbroken straight line in Fig. 4 represents a linear dependence of spin count on ferric-to-total-iron ratio, as would be expected if the observed ESR signals were to arise from $\mathrm{Fe}^{3+}$. These data are taken to be a strong indication that the $\mathrm{X}$ resonance, and perhaps the $\mathrm{Z}$ resonance as well, do not arise from ferric iron. The broad flat "background" signal revealed at 10x gain in Fig. 3c could, for example, turn out to be due to the $\mathrm{Fe}^{3+}$ in the sample. Its intensity could be weak due to strong coupling of antiferromagnetic pairs and/or to strong "crystal field" broadening" that causes much of the spectral intensity to lie above the range of magnetic fields experimentally scanned $(0-1000 \mathrm{mT})$.

The ESR signals of the iron phosphate glasses resemble nothing else in the literature except the correspondingly denoted signals in iron-free amorphous peroxyborate (APB) 
preparations. ${ }^{3,}{ }_{4}^{4}$ APBs are prepared from polycrystalline $\mathrm{NaBO}_{3} \cdot \mathrm{H}_{2} \mathrm{O}$ by gently heat treating at $\sim 120 \mathrm{C}$, causing amorphization, presumably the loss of some water and hydrogen, and the development of an intense paramagnetism $\sim 0.35$ spins per boron due to various paramagnetic states of oxygen. Figure 5a compares the X-band spectra of an APB preparation recorded at $77 \mathrm{~K}$ with the spectrum of the unirradiated $\mathrm{PO}_{4}-3$ glass measured at $450 \mathrm{~K}$. (The sharp lines noted at high field values for the APB spectrum are due to oxygen molecules released into the initially evacuated sample tube by this "pseudosuperoxide" material.) Figure 5b shows that the X resonances in the APBs and the iron phosphate glasses share another unusual property, namely, each exhibits a power-law dependence of ESR linewidth on temperature. While such dependencies have been reported for antiferromagnetic crystals (e.g., $\mathrm{MnF}_{2}$ ) within $10^{\circ} \mathrm{K}$ of the Néel temperature, ${ }^{5}$ to our knowledge only the APBs and the iron phosphate glasses display such dependencies over temperature ranges $\sim 300-400^{\circ} \mathrm{K}$.

In the APBs, the precise origin of the $\mathrm{X}$ resonance has never been well understood since its discovery over 30 years ago, ${ }^{3,}{ }^{4}$ beyond the general inference that it arises in some way from superoxide ions $\left(\mathrm{O}_{2}^{-}\right)$. The Principal Investigator now hypothesizes that a continuous random network of boron-oxygen tetrahedra could account for the observed magnetic properties, if it is assumed that two of the apices of each tetrahedron are occupied by oxide ions $\left(\mathrm{O}^{2}-\right)$ and the other two by superoxide ions $\left(\mathrm{O}_{2}{ }^{-}\right)$. Theoretical calculations ${ }^{6}$ have indicated that a superoxide ion could occupy a bridging position even in $\mathrm{SiO}_{2}$. In the ideal case of a pure boron oxide glass, the chemical formula would be $\mathrm{BO}_{3}$ or, more precisely $\mathrm{BO}\left(\mathrm{O}_{2}^{-}\right)$, which would be structurally isomorphous with $\mathrm{SiO}_{2} \cdot \mathrm{BO}\left(\mathrm{O}_{2}^{-}\right)$is analogous to glassy BOF, reported on recently. ${ }^{7}$ The large Lorentzian linewidth observed for the APBs is here envisioned to arise from superexchange interactions along the selfavoiding linear chains

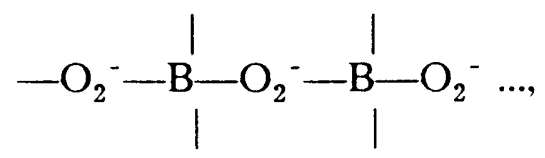

which perforce must wend through the postulated three-dimensional network. In the alkalioxide-containing APBs, the $\mathrm{Z}$ resonance has been reliably demonstrated ${ }^{1-3}$ to be due to isolated $\mathrm{O}_{2}{ }^{-}$ions, quite possibly located in an amorphous sodium peroxide phase separated from the continuous boron-oxygen network. Note that the following reaction, to the extent it may take place during the $120-\mathrm{C}$ heat treatment, could convert the perborate monohydrate precursor to $\mathrm{BO}_{3}$ and sodium peroxide:

$\mathrm{NaBO}_{3} \cdot \mathrm{H}_{2} \mathrm{O} \rightarrow 1 / 2 \mathrm{Na}_{2} \mathrm{O}_{2}+\mathrm{BO}_{3}+\mathrm{H}_{2} \uparrow$.

Moderate numbers of superoxide ions are always found in $\mathrm{Na}_{2} \mathrm{O}_{2}$ and exhibit a characteristic ESR spectrum." The demonstration that the $\mathrm{Z}$ resonance in the APBs arises from $\mathrm{O}_{2}{ }^{-}$ions in an amorphous matrix is securely founded on semi-empirical computer line-shape simulations based on the g-value theory of superoxide ions given by Känzig and Cohen. ${ }^{8}$ 
However, the $\mathrm{Z}$ resonances of Figs. 1 and 3 cannot be subjected to this definitive test because the $\mathrm{g}$ matrices in the case of the as-melted iron phosphate glasses are isotropic and essentially coincident with the free electron $g$ value. Nevertheless, a model will be proposed below which can account for these isotropic $\mathrm{Z}$ resonances, still assuming an $\mathrm{O}_{2}{ }^{-}$origin.

Of all the glasses provided by Savannah River, only the iron phosphate glass showed an especially obvious effect of $\gamma$ irradiation on the recorded ESR spectra. Figure 6 reveals that the irradiated glass is characterized by a substantially stronger $\mathrm{Z}$ resonance relative to that present before irradiation. In particular, the radiation-induced $\mathrm{Z}$ resonance in the $\mathrm{PO}$,3 glass is anisotropic (see the subtraction spectrum of Fig. 6b). Although computer simulation of this subtraction spectrum has not yet been completed, the spectrum appears to the eye to fit the Känzig-Cohen theory ${ }^{8}$ for isolated (non-exchange-interacting) $\mathrm{O}_{2}{ }^{-}$ species. If confirmed by further study, the ability to generate copious numbers of isolated $\mathrm{O}_{2}{ }^{-}$ions by irradiation will provide strong support for a model wherein even larger numbers of superoxide ions are already present in the as-melted glass network.

Based on the early results of the present ESR study, samples of the irradiated and unirradiated $\mathrm{PO}_{4}-3$ glasses were sent to Prof. H. Imagawa, an unfunded Co-Investigator at Toyo University in Japan, for mass-spectroscopic determination of gas evolution under ramped heating under high vacuum $\left(10^{-10} \mathrm{~atm}\right){ }^{9}$ Some results for the irradiated glass are shown in Fig. 7. Here, 0, gas is seen to evolve in two distinct peaks near $1170 \mathrm{C}$ and 1350 C. The original melt temperature of $1450 \mathrm{C}$ is vividly marked as the termination of $\mathrm{O}_{2}$ evolution and a pickup of $\mathrm{H}_{2} \mathrm{O}$ evolution (a pickup in $\mathrm{H}_{2}$ evolution above $1450 \mathrm{C}$ was also noted). The results for the unirradiated glass were qualitatively similar in all of these regards but did show quantitative differences which, if reproducible, might be interpretable as true radiation effects. More studies of this type will be required to decide this question. In addition, a reliable absolute calibration relating ion current to numbers of molecules is yet to be performed. This calibration will be critical to any proof that the iron phosphate glasses contain superoxide ions as a major chemical component.

Studies of a PO,-3 glass by isochronal annealing (ESR) and ramped heating (DTA) showed a one-for-one conversion of the $\mathrm{X}$ resonance to the $\mathrm{Z}$ resonance upon partial crystallization near $670 \mathrm{C}$ and a $\mathrm{Z} \rightarrow \mathrm{X}$ reconversion upon partial remelting near $970 \mathrm{C}$. This interconversion of the two characteristic resonances is strong evidence that both arise from the same paramagnetic species, here advocated to be $\mathrm{O}_{2}{ }^{-}$. The ESR experiment (see Fig. 8) had to be terminated at $1070 \mathrm{C}$ due to breakage of the evacuated fused silica tubes containing the samples. However, by this point multiple sharp peaks had appeared near the high-field end of the spectrum, similar to the lines shown in Fig. 5a for an APB sample. These sharp lines are unambiguously recognized as rotational-vibrational transitions of oxygen gas, ${ }^{10}$ in the present case 0 , molecules evolved from the iron phosphate glass PO,-3. Ramped heating of separate samples of this material to $1070 \mathrm{C}$ in dry Ar (TGA) resulted in a weight loss of $-4 \%$. These TGA data are plotted in Fig. 8 under an arbitrary model assumption that the entire weight loss was due to evolution of oxygen molecules. The integral of Prof. Imagawa's 0, ion currents are also plotted in Fig. 8, normalized (in the 
temporary absence of an absolute calibration) to the Principal Investigator's model prediction of $3 / 4$ of an oxygen molecule per phosphorus This model will be explained below.

Peroxo acids of boron and phosphorus are both stable compounds? Sodium peroxyborate is the sodium salt of peroxo boric acid which, by gentle heating, can be converted to APBs, ${ }^{4}$ which have been argued above to contain superoxide ions in a glass-like network. If it is accepted that peroxo boric acid can be the precursor of such a mixed oxide/superoxide glass, then the existence of a phosphorus analog cannot be ruled out. With regard to the iron phosphate glasses studied here, peroxo phosphoric acid was not used as a precursor. Any excess oxygen in these glasses then must result from either (i) evolution of acid hydrogen during melting of glasses batched from phosphoric acid or (b) pickup of oxygen from the melt atmosphere. Assuming for the sake of argument that one of these mechanisms pertains, the Principal Investigator's model for the phosphorus-oxygen part of the glass network is $\mathrm{PO}$, or, more precisely $\mathrm{PO}_{2}\left(\mathrm{O}_{2}{ }^{-}\right)$, which like $\mathrm{BO}$, can also be viewed as an $\mathrm{SiO}_{2}$ analogue. In the present case, the coordination polyhedron would be a trigonal bi-pyramid, joined at four of its five apices to identical neighboring polyhedra. There are two ways that the superoxide ion can be incorporated in these polyhedra. First, the $\mathrm{O}_{2}{ }^{-}$ions could occupy nonbridging positions (one per phosphorus), allowing the polyhedra to be linked by four normal oxide ions:<smiles>CO[PH]([O-])([O-])O[PH]([O-])(O)OC</smiles>

(Note that the fourth bridging oxygen bond is suppressed in this schematic two-dimensional representation.) In this case, exchange interactions between the superoxide ions would be moderated by three intervening non-magnetic ions, P-O-P, perhaps resulting in an exchangenarrowed ESR signal, as seems to be the best explanation of the $\mathrm{Z}$ resonance in the iron phosphate glasses.

The second possibility is that the superoxide ions occupy bridging positions and a normal oxide ion $\left(\mathrm{O}^{2-}\right)$ is found at the nonbridging position:<smiles>COP(O)(OC)=[O+][PH](C)(O)OC</smiles> 
where the top oxygens are to be regarded as nonbridging and, again, there is understood to be an additional bridging oxide ion which is suppressed in this schematic two-dimensional representation. It is clear that structure (4) is (except for the nonbridging oxide ion) fully isomorphic to structure (1). In particular, the linear chains, $-\mathrm{P}-\mathrm{O}_{2}{ }^{-}-\mathrm{P}-\mathrm{O}_{2}{ }^{-}-\ldots$, are analogous to the ones here postulated to exist in the APBs. As in the latter case, these are postulated to be the origin of the (presumably exchange broadened) $\mathrm{X}$ resonance in the iron phosphate glasses. (In the future it is planned to involve a theorist in calculating the effects on ESR linewidth of superexchange interactions along such chains.) With this model it is possible to postulate the reason for the $X \rightarrow Z \rightarrow X$ transformations on crystallization and remelting, namely, these could be due to a phase transformation from structure (4) to structure (3) and back again. The atomic displacements required for such a transition would be relatively small.

This model can also explain the evolution of oxygen gas observed by Prof. Imagawa, according to the following decomposition reaction:

$2 \mathrm{PO}_{4} \rightarrow \mathrm{P}_{2} \mathrm{O}_{5}+(3 / 2) \mathrm{O}_{2} \uparrow$.

If our model is correct, the structure of the iron phosphate glasses is different from those of any other glass known or even hypothesized. As such, there would clearly be much new physics, chemistry, and materials science to be investigated. For example, reasons for the observed high chemical durability of the iron phosphates would have to be reconsidered in light of the model. Indeed, a superoxide ion bonded into a glass network (represented by G-O-O ; where "•" denotes an unpaired electron) would react with water by a non-polar mechanism, possibly:

$\mathrm{G}-\mathrm{O}-\mathrm{O} \cdot+\mathrm{H}_{2} \mathrm{O} \rightarrow \mathrm{G}-\mathrm{O}-\mathrm{O}-\mathrm{H}+\cdot \mathrm{OH}$.

Presumably, the resulting hydroxyl radicals would dimerize to form hydrogen peroxide:

$2 \cdot \mathrm{OH} \rightarrow \mathrm{H}_{2} \mathrm{O}_{2}$.

The effects of long term radiation on these glasses would also have to be carefully investigated. The experimental data of Fig. 4 are suggestive that $\gamma$ irradiation may separate superoxide ions from the network into interstitial phases, at least in the case of the alkalicontaining $\mathrm{PO}_{4}^{-3}$ glass. More work will be needed to confirm if this is the correct interpretation and whether or not it is also the case for the binary iron phosphates (which have not yet been subject to ESR studies following irradiation). These and other nuclear waste glass issues will be intensively investigated in the second and third years of this interagency agreement. 
References

1. R. Cases and D.L. Griscom, Nucl. Inst. Methods B1 (1984) 503 .

2. D.L. Griscom, in Glass: in Science and Technology Vol. 4B, D.R. Uhlmann and N.J. Kreidl, Ed. (Academic Press, Boston, 1990), pp. 151-251.

3. D.L. Griscom, Ph.D. Thesis, Brown University, Providence, RI, 1966.

4. J.O. Edwards, D.L. Griscom, R.B. Jones, K.L. Waters, and R.A. Weeks, J. Am. Chem. Soc. 91 (1969) 1095.

5. $\quad$ Burgiel and Strandberg, J. Chem. Phys. 26 (1965) 865.

6. A.H. Edwards and W.B. Fowler, Phys. Rev. B26 (1982) 6649.

7. C. Boussard-Pledel, G. Fonteneau, and J. Lucas, J. Non-Cryst. Solids 188 (1995) 147.

8. W. Kanzig and M.H. Cohen, Phys. Rev. Lettr. 3 (1959) 509.

9. H. Imagawa, M. Aoyagi, K. Satoh, and S. Uchiyama, Glastech. Ber. Sci. Tech. 68 C2 (1995) 217.

10. W.E. Henry, Phys. Rev. 80 (1950) 396.

11. N.-G. Vannerberg, in Progress in Inorganic Chemistry 4 (1962) 125-197. 


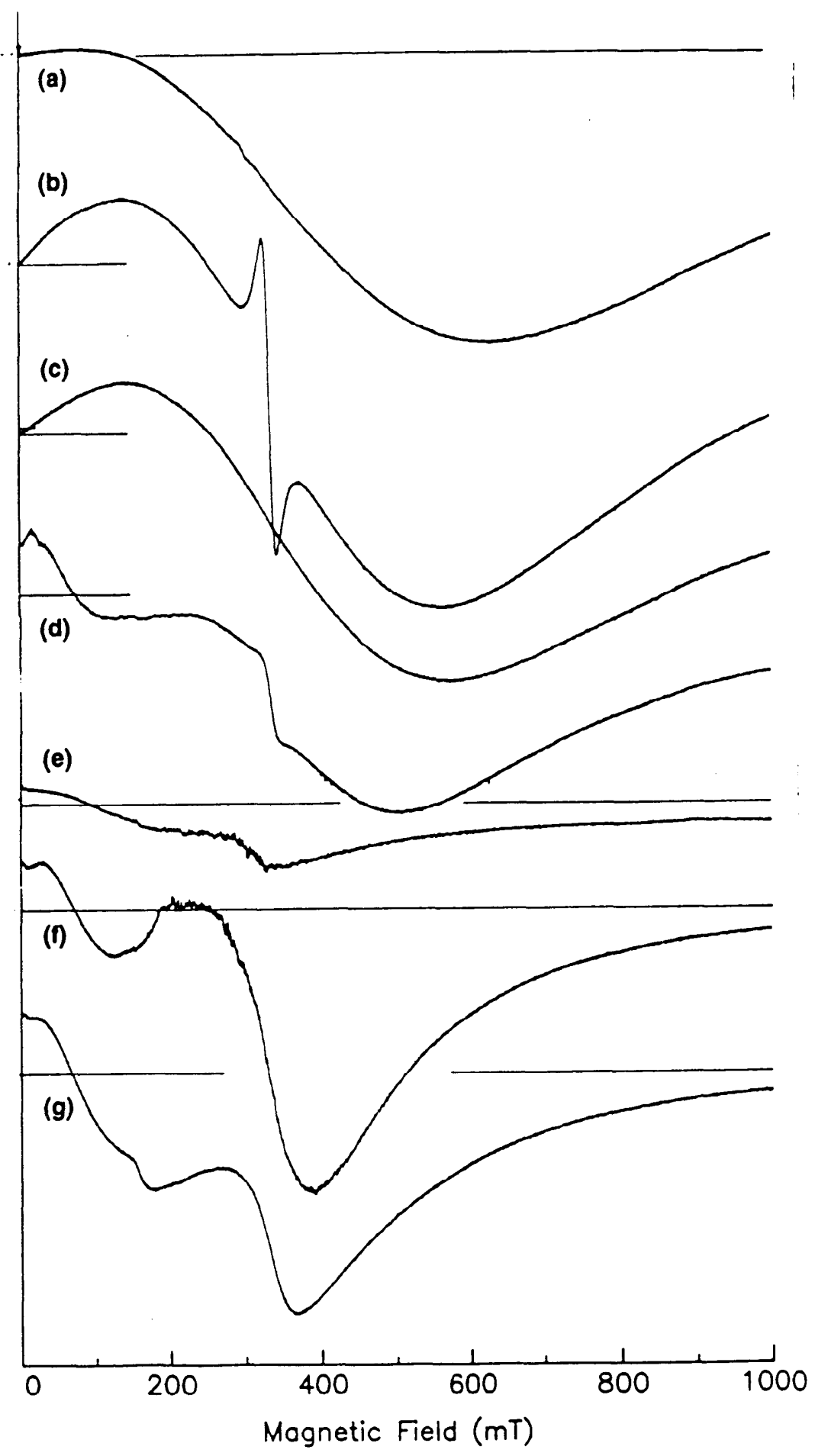

Fig. 1 X-band first-derivative ESR spectra recorded at room temperature for $(a, b, c, d)$ four iron phosphate glass compositions (see Table 1), (e) a lanthanum-silicate composition, and (f,g) two DWPF glasses. Spectrometer gains were identical for (a) through (e) and x 1/4 for (f) and (g). 


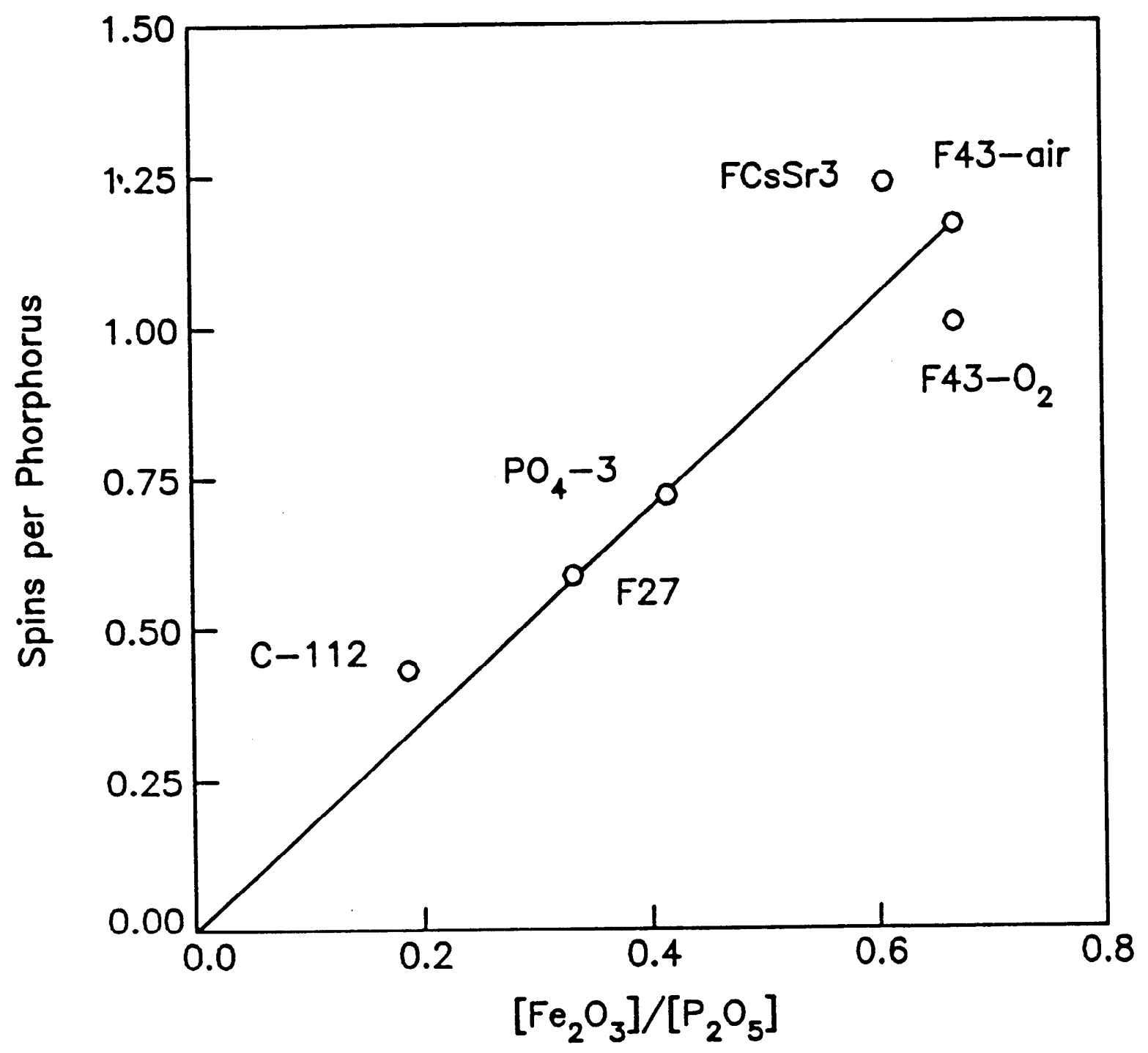

Fig.2 ESR spin concentrations, expressed as number of spin- ${ }^{1 / 2}$ states per phosphorus atom, versus the molar ratio of iron oxide $\left(\right.$ as $\left.\mathrm{Fe}_{2} \mathrm{O}_{3}\right)$ to phosphorus oxide $\left(\right.$ as $\left.\mathrm{P}_{2} \mathrm{O}_{5}\right)$ for several iron phosphate glass melts. 


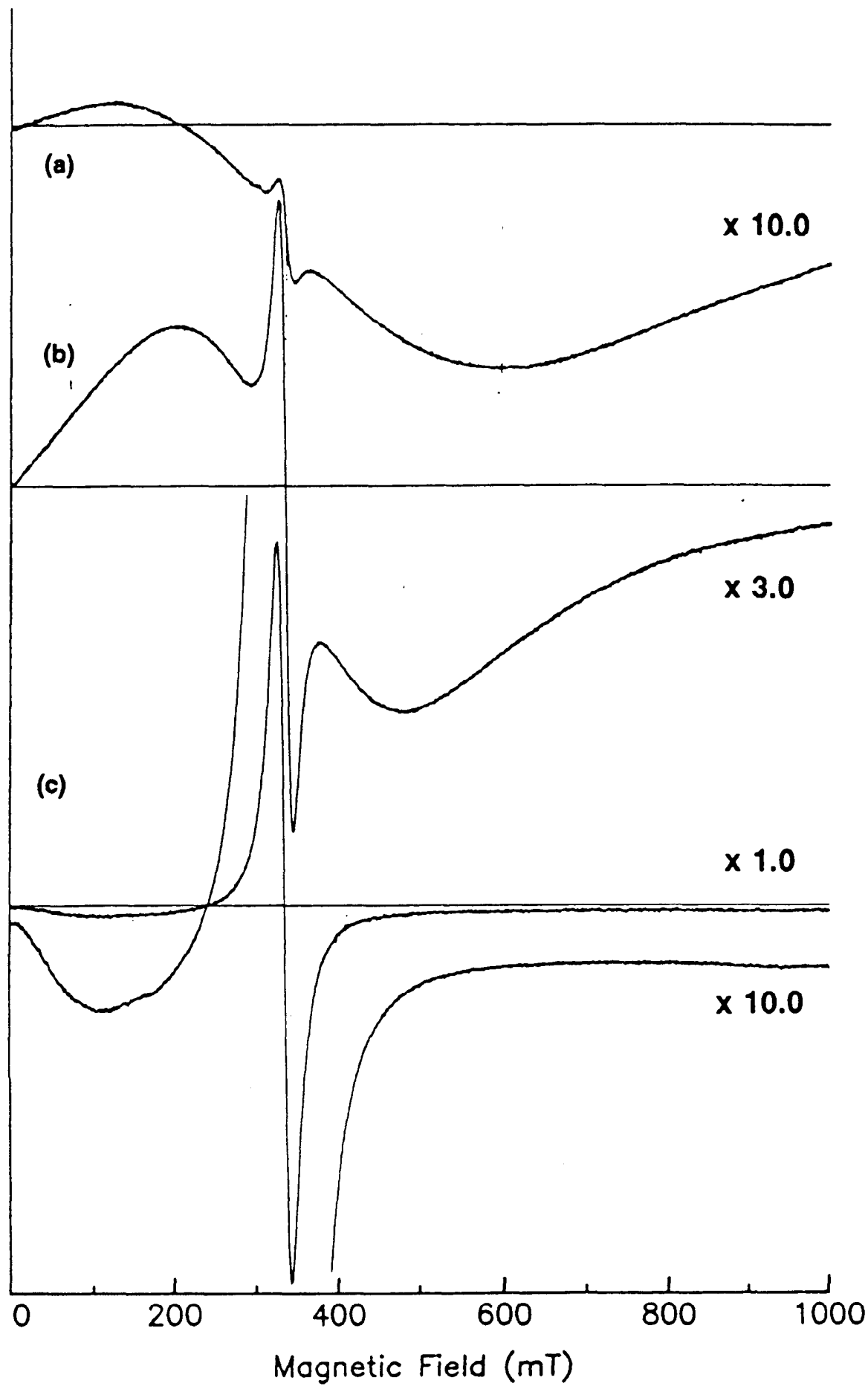

Fig.3 X-band first-derivative ESR spectra recorded at room temperature for identically batched binary iron phosphate glasses (composition F-43 of Table 1) melted under (a) air, (b) bubbled 0 , and (c) $90 \%$ forming gas $/ 10 \%$ air. Spectrometer gains indicated to the right represent the product of sample mass times magnetic field modulation amplitude. 


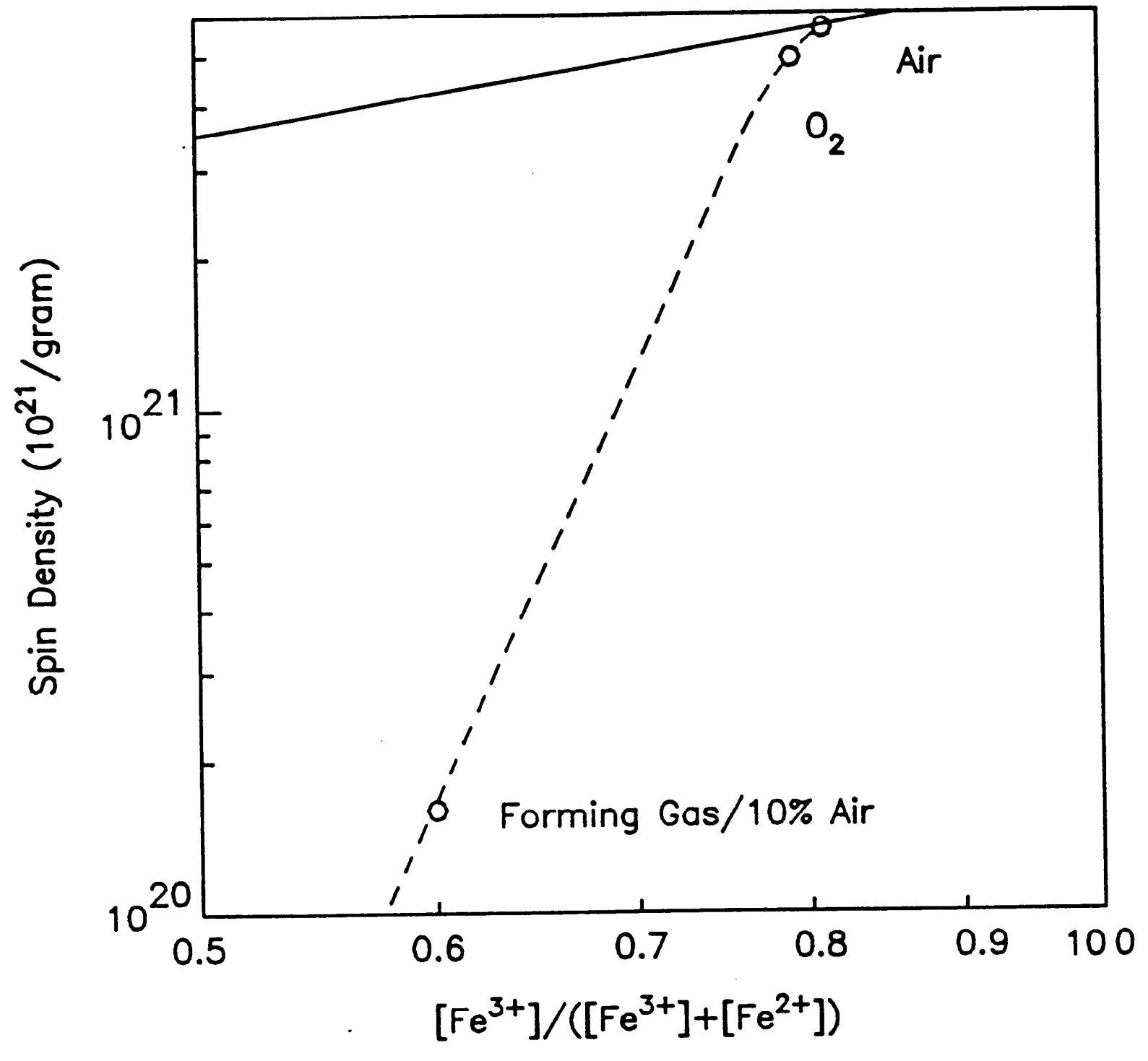

Fig.4 Log-log plot of ESR spin densities determined by Lorentzian fits of the X-resonanceplus-Z-resonance spectra of Fig. 3 versus the ferric-iron:total-iron ratio determined by Mössbauer spectroscopy (the latter data were provided by G.K. Marasinghe). The dashed curve is drawn as an aid to the eye; the unbroken line represents the linear relationship to be expected if the ESR signals were to arise from $\mathrm{Fe}^{3+}$. 


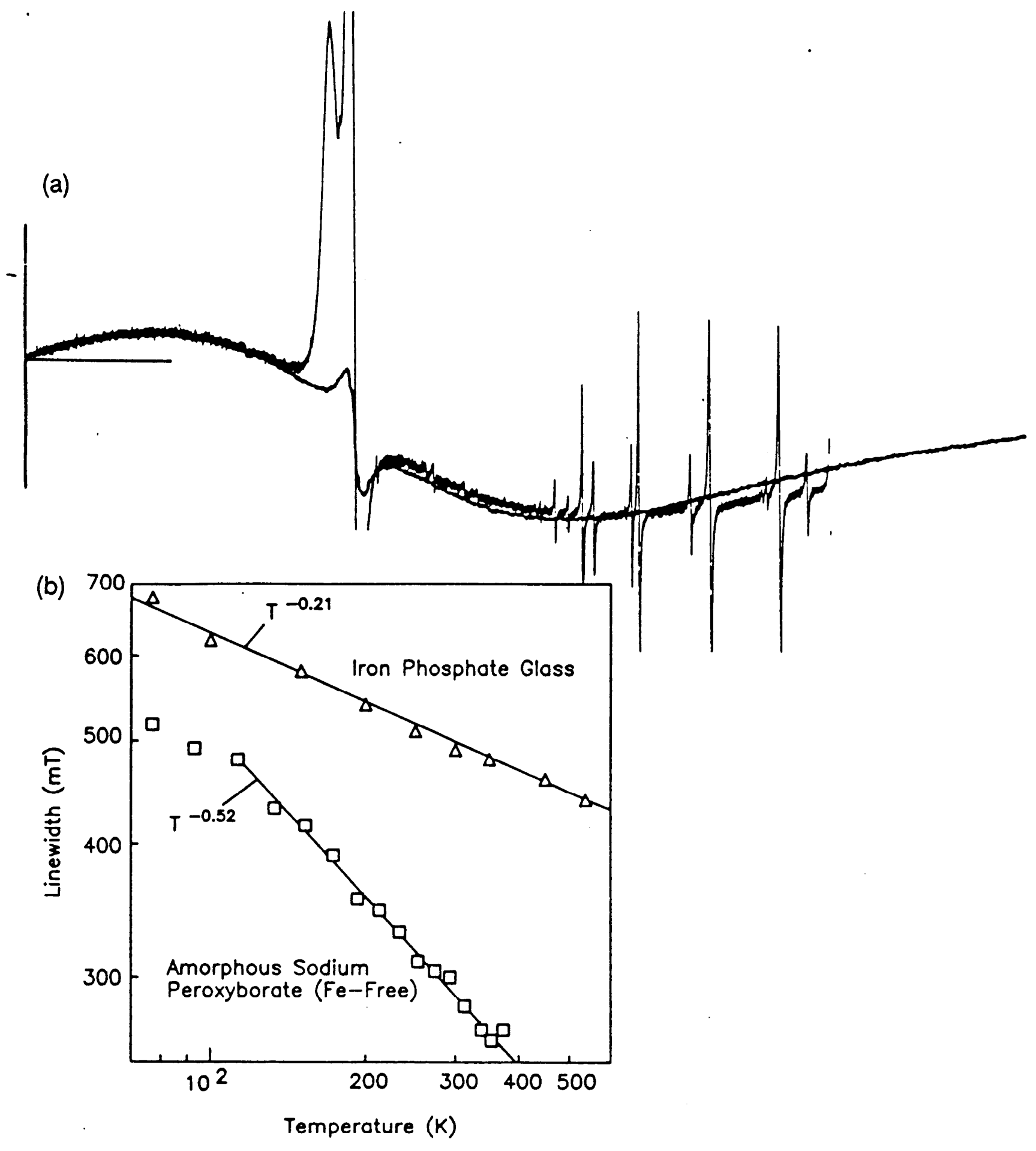

Fig.5 (a) X-band first-derivative ESR spectra recorded at $77 \mathrm{~K}$ for and amorphous peroxyborate preparation ${ }^{3}$ (thicker curve with sharp high-field lines) and at $450 \mathrm{~K}$ for iron phosphate glass $\mathrm{PO}_{4}-3$. (b) temperature dependencies of the $\mathrm{X}$-resonance linewidth in these two materials. 

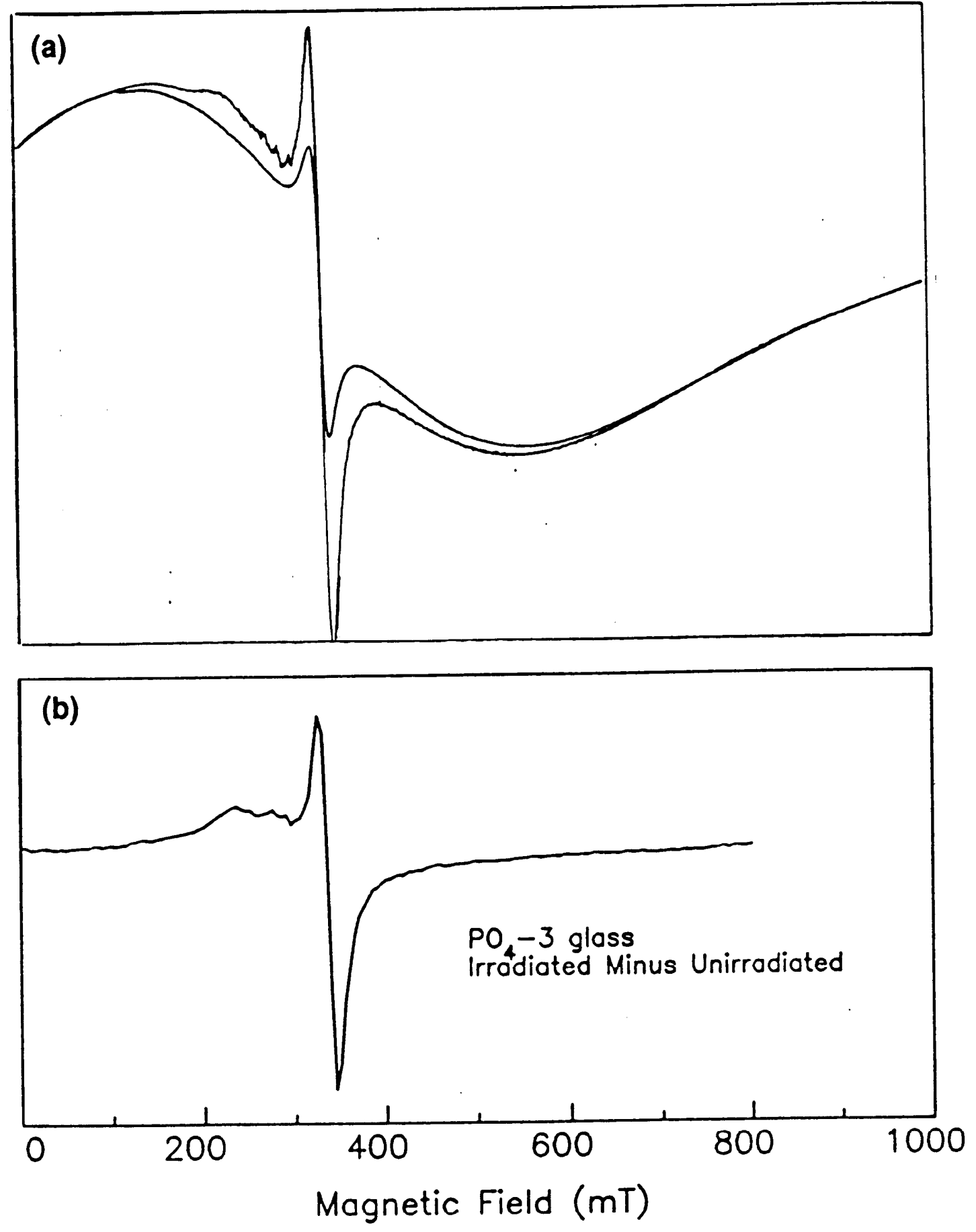

Fig.6 (a) X-band first-derivative ESR spectra recorded at room temperature for samples of iron phosphate glass $\mathrm{PO}_{4}-3$ before (weaker central resonance) and after $\gamma$ irradiation to a dose of $3 \times 10^{7}$ Gy (stronger central resonance). (b) Radiation-induced spectrum: difference between the two spectra of (a). 


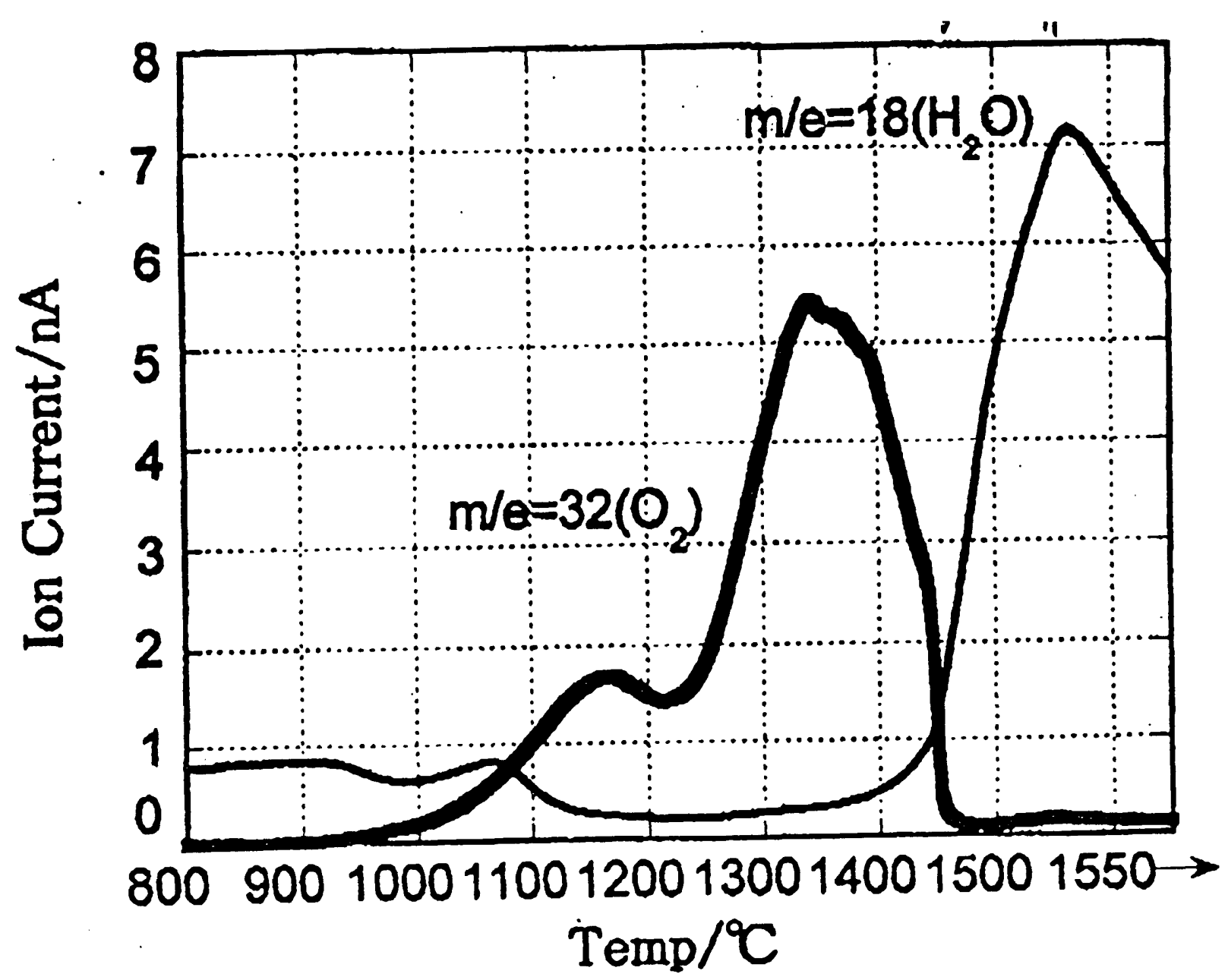

Fig.7 Ion currents recorded by a quadrupole mass analyzer during ramped heating of an ${ }^{d}$ irradiated sample of iron phosphate glass $\mathrm{PO}_{4}-3$ in high vacuum. (These data were provided by $\mathrm{H}$. Imaglawa.) Calibration of these data in terms of the number of oxygen molecules evolved per unit temperature interval are not yet completed. 


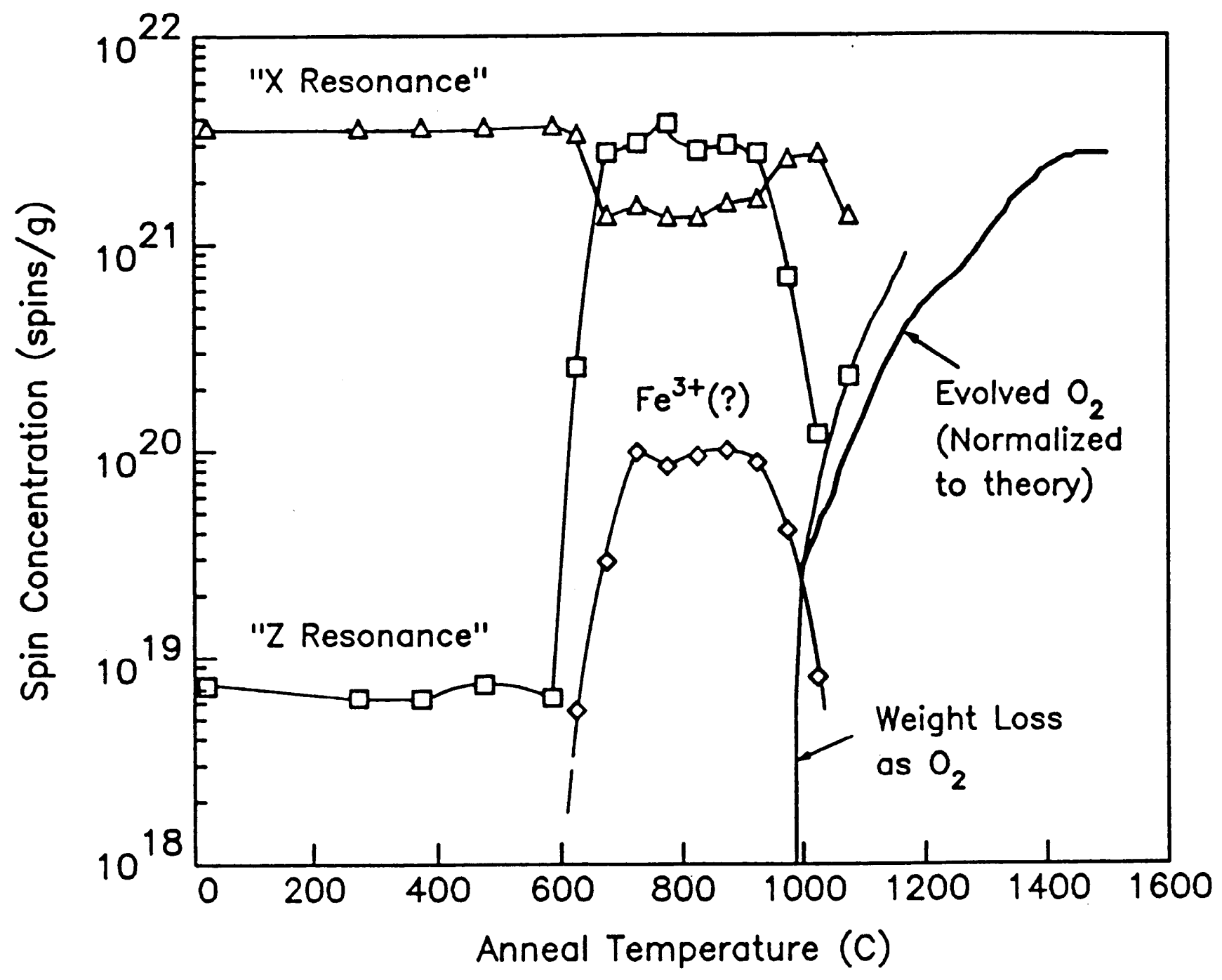

Fig.8 Results of ESR isochronal anneal experiments (data points) and of ramped heating TGA (thin curve) and oxygen gas evolution (bold curve) for $\gamma$-irradiated iron phosphate glass of composition PO,-3. ESR data for an unirradiated sample were similar, except for the absence of a signal tentatively ascribed to $\mathrm{Fe}^{3+}$ ion pairs (diamonds); these data are shown here with arbitrarily normalization. 